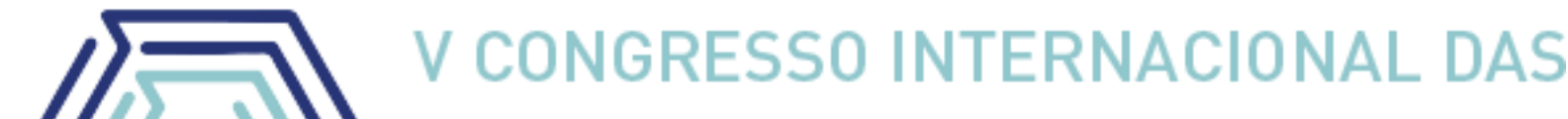 LICENCIATURAS COINTER - PDVL 2018
}

\section{A RÉGUA DE GOLOMB COMO FERRAMENTA DE AUXÍLIO PARA A FORMAÇÃO INICIAL DE PROFESSORES}

\section{THE GOLOMB RULER AS A TOOL FOR INITIAL TEACHER TRAINING}

\author{
Apresentação: Pôster \\ Laura Maria dos Santos Medeiros Pereira ${ }^{1}$; Emanuel Gomes Lourenço ${ }^{2}$; Rafael Pereira de \\ Melo $^{3}$
}

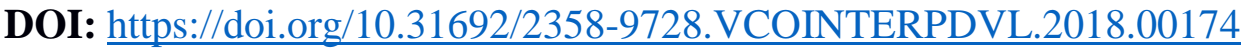

\section{Introdução}

O presente trabalho tem como objetivo utilizar a pouco conhecida régua de Golomb como instrumento metodológico de auxílio, buscando uma melhor formação inicial de professores da educação básica brasileira.

Toma como ponto de partida a utilização de conceitos formados em estudos a serem realizados sobre a Régua de Golomb, uma diferente ferramenta que, ao contrário das réguas usuais, a diferença entre quaisquer duas marcas correspondem a uma distância que não é medida por nenhuma outra marca, para suprir a necessária fundamentação pedagógica nas formações iniciais dos nossos professores que, conforme citam as diretrizes de formação do MEC, tem sido deficiente.

De acordo com os dados do Censo da Educação Superior 2013 (último levantamento divulgado), existem 7.900 cursos de licenciatura na área de educação espalhados portodo país. Neste ano, mais de 200 mil alunos foram licenciados (56\% pela modalidade presencial e $44 \%$ pelo ensino à distância). Porém, especialistas na área apontam que muitos cursos ainda estão bastante distantes da realidade da sala de aula.

As questões a serem enfrentadas na formação inicial são históricas. No caso da formação nos cursos de licenciatura, em seus moldes tradicionais, a ênfase está contida na formação nos conteúdos da área, onde o bacharelado surge como a opção natural que possibilitaria, como apêndice, também, o diploma de licenciado. Refere-se aqui a "diploma" e

\footnotetext{
${ }^{1}$ Licenciatura em Matemática, IFRN, laura.medeiros@academico.ifrn.edu.br

${ }^{2}$ Mestre em Matemática, IFRN, emanuel.lourenco@ifrn.edu.br

${ }^{3}$ Mestreem Matemática, IFRN, rafael.melo@ifrn.edu.br
} 
não à "formação", pois se trata muito mais de uma certificação formal, após o cumprimento de créditos burocraticamente definidos para a área pedagógica, do que preparação integrada que propicie uma reflexão dos conteúdos da área com a realidade específica da atuação docente. (MEC 2000)

Nesse sentido, trazemos a Régua de Golomb como ferramenta para criação de materiais didáticos a serem utilizados em formações iniciais de professores, sendo ela uma facilitadora de muitos conteúdos e situações matemáticas.

Na matemática, uma régua de Golomb é um conjunto de marcas em posições inteiras ao longo de uma régua imaginária, de modo que não haja dois pares de marcas à mesma distância. O número de marcas na régua é sua ordem e a maior distância entre duas de suas marcas é seu comprimento, a menor marca é habitualmente colocada em 0 e a próxima marca no menor de seus dois valores possíveis.

Unindo tudo isso, apresentamos uma proposta para culminar em materiais didáticos auxiliadores em conteúdos didáticos a serem definidos ao longo da pesquisa, resolução de situações problemas e exercícios, mas principalmente, materiais formadores de indivíduos que devem estar melhor preparados para entrar em uma sala de aula.

\section{Fundamentação Teórica}

O MEC (2000) afirma que um dos problemas centrais dos cursos de formação é a falta de articulação entre os chamados conteúdos pedagógicos e os conteúdos a serem ensinados. Isso se mostra muito nitidamente nos cursos de licenciatura, compostos por dois grupos de disciplinas. Em um grupo, estão as disciplinas de formação específica na área e, no outro, estão as disciplinas de formação geral e pedagógica. Geralmente, esses dois grupos de disciplinas são desenvolvidos de forma desarticula e, até mesmo, contraditória. A partir deste ponto, a presente pesquisa propõe o estudo de uma ferramenta pouco conhecida chamada Régua de Golomb, para ser utilizada na elaboração de materiais didáticos que irão auxiliar na formação inicial de professores para a educação básica.

De acordo com os dados do Censo da Educação Superior 2013 (último levantamento divulgado), existem 7.900 cursos de licenciatura na área de educação espalhados portodo país. Neste ano, mais de 200 mil alunos foram licenciados (56\% pela modalidade presencial e $44 \%$ pelo ensino à distância). Porém, especialistas na área apontam que muitos cursos ainda estão 
bastante distantes da realidade da sala de aula.

As questões a serem enfrentadas na formação inicial são históricas. No caso da formação nos cursos de licenciatura, em seus moldes tradicionais, a ênfase está contida na formação nos conteúdos da área, onde o bacharelado surge como a opção natural que possibilitaria, como apêndice, também, o diploma de licenciado. Refere-se aqui a "diploma" e não à "formação", pois se trata muito mais de uma certificação formal, após o cumprimento de créditos burocraticamente definidos para a área pedagógica, do que preparação integrada que propicie uma reflexão dos conteúdos da área com a realidade específica da atuação docente. (MEC 2000)

Nesse sentido, trazemos a Régua de Golomb como ferramenta para criação de materiais didáticos a serem utilizados em formações iniciais de professores, sendo ela uma facilitadora de muitos conteúdos e situações matemáticas.

Na matemática , uma régua de Golomb é um conjunto de marcas em posições inteiras ao longo de uma régua imaginária, de modo que não haja dois pares de marcas à mesma distância. O número de marcas na régua é sua ordem e a maior distância entre duas de suas marcas é seu comprimento, a menor marca é habitualmente colocada em 0 e a próxima marca no menor de seus dois valores possíveis.

\section{Metodologia}

O projeto será realizado em QUATRO etapas, de caráter qualitativo, a saber:

$1^{\text {a }}$ ETAPA: Fundamentação teórica.

A primeira etapa será constituída de pesquisa e estudos sobre a Régua de Golomb, sua origem, seu funcionamento, suas aplicações e suas variações. Será fundamentado também, como a mesma é utilizada e aplicada em diversos conteúdos do ensino básico.

$2^{\text {a }}$ ETAPA: Elaboração dos materiais.

$\mathrm{Na}$ segunda etapa, já com os conhecimentos adquiridos, serão feitos os materiais didáticos para a formação dos professores, utilizando a régua como principal ferramenta facilitadora. 


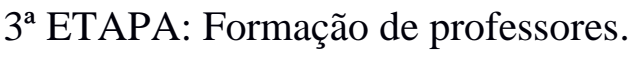

Durante a terceira etapa vai acontecer a formação de professores com os materiais criados durante a pesquisa. Os alunos, que serão do curso de Licenciatura em Matemática do IFRN - Natal Central, além de receberem a formação, serão convidados a avaliar a compreensão dos materiais.

$4^{\mathrm{a}}$ ETAPA: Publicação dos materiais.

Por fim, os materiais elaborados nesta pesquisa vão ser submetidos ao https://memoria.ifrn.edu.br/, que é o repositório institucional de armazenamento da produção acadêmica do IFRN, como também, os frutos da pesquisa serão submetidos para exposição no XIII ENEM (Encontro Nacional de Educação Matemática) que acontecerá em 2019.

\section{Resultados e Discussões}

Por tratar-se de um projeto em andamento, este apresenta resultados esperados enumerados abaixo:

- Conhecimento teórico e prático da utilização da Régua de Golomb.

- Materiais didáticos elaborados e prontos para utilização na formação inicial de professores.

- Realizar a formação com alunos da Licenciatura em Matemática do IFRN - Natal Central.

- Propor a execução de um projeto para propagação dessa formação para demais professores, tendo em vista um baixo conhecimento da Régua de Golomb.

- Submeter os resultados da pesquisa em congressos como o XII ENEM em 2019 e também no Memória IFRN.

\section{Conclusões}

Com este trabalho, esperamos promover o conhecimento sobre a pouco conhecida Régua de Golomb, utilizando-a como ferramenta metodológica para a formação inicial de professores. Para isso, a elaboração do material didático com uma proposta nova trás para os futuros professores uma nova possibilidade de transmitir determinados conteúdos, proporcionando a possibilidade de entrar em sala de aula com uma proposta diferente, saindo 
da tão comum educação tradicional que leva a matemática a ser problematizada pela maioria dos alunos da educação básica.

\section{Referências}

BRASIL. MEC. Diretrizes para a formação inicial de professores da educação básica, em curso de nível superior. Questões a serem enfrentadas na formação inicial. p.21. Disponível em <http://portal.mec.gov.br/cne/arquivos/pdf/basica.pdf>

Régua de Golomb. Disponível em <https://en.wikipedia.org/wiki/Golomb_ruler> Acessado em $16 / 05 / 18$ às $17: 11$

AZEVEDO, R. O.M.; GHEDIN, E. Formação inicial de professores da educação básica no Brasil: trejetória e perspectivas. Disponível em <file:///C:/Users/20161014300009.IFRN/Downloads/dialogo-7214.pdf>

KURPEL,D. V.; SCARPIN, C. T.; PÉCORA JUNIOR, J. E.; CHOUEIRI, A.C.; SCHENEKEMBERG, C. M.; SILVA, N. C. O. Uma nova técnica de resolução para o Problema da Régua de Golomb. Simpósio de Métodos Numéricos em Engenharia. Disponível em <https://eventos.ufpr.br/smne/SMNE2017/paper/viewFile/583/258> 